\title{
Bio sorption Studies of Chromium Ions with Modified Chicken Feathers
}

\author{
Rakesh KE and Rosy Antony* \\ Research Department of Chemistry, Nirmalagiri College, India
}

Received: November 15, 2017; Published: December 01, 2017

*Corresponding author: Rosy Antony, PG and Research Department of Chemistry, Nirmalagiri College, Kuthuparamba-670701, India; Email: drrosy.antony3@gmail.com

\begin{abstract}
Modified chicken feather has been used as biosorbent for removing chromium ions from aqueous solution. The adsorption capacity tests were performed on an equilibrium batch basis. The parameters such as contact time, biosorbent dose, pH etc were optimized and were found to be $2 \mathrm{hrs}, 100 \mathrm{mg} \& \mathrm{pH}$ 6.0. Equilibrium isotherms were analyzed for the adsorption process and Freundlich adsorption isotherm model was found to fit the data well. The kinetics of adsorption followed pseudo-second order model.
\end{abstract}

Keywords: Modified Chicken Feather; Bio sorption; Chromium ions; Freundlich isotherm; Pseudo second order

\section{Introduction}

Heavy metals such as $\mathrm{Hg}, \mathrm{Pb}, \mathrm{As}, \mathrm{Cr}$, etc are harmful to soil, water bodies and aquatic life. They are leached out mainly from industrial wastes, mines and research labs [1]. They produce acute toxicity in plants, animals and micro organisms. Due to bio accumulation and bio magnification through food chain they cause chronic effects even at lower concentrations. Heavy metals are generally removed from environment by precipitation, reverse osmosis, coagulation, flocculation etc [2-7]. These processes have many drawbacks, which include selective or partial removal of metal ions and high operational cost. Bio sorption can be used for effective removal of the heavy metals from environment. The major advantages of biosorption are low cost, high efficiency, regeneration, metal recovery etc. Bio sorption is largely influenced by $\mathrm{pH}$, the concentration of biomass and the interaction time.

A very big problem of the agriculture industry is managing the enormous amount of waste generated by poultry processing enterprises. The scientific usage of feathers as a renewable material offers both economic and environmental benefits. The adsorbing ability of chicken feathers (CF) as potential biosorbent for the removal of hazardous substances from effluents is due to their high surface area and several reactive functional groups [8-11]. CF consists of keratinous proteins with many functional groups such as $-\mathrm{COOH},-\mathrm{NH}_{2}$, S-S- which can be treated with suitable chemical reagents to get chemically modified $\mathrm{CF}$ biosorbent.

\section{Experimental}

The reagents used were ethanol, methanol and $\mathrm{HCl}$ and were of analytical grade. UV-Visible spectrophotometer (shimadzu-1800), Mechanical shaker (Rotek, Model number REC27255A2), pH meter, XRD (Rigaku Miniflex X-ray Diffractometer with $\mathrm{Cu} \mathrm{K} \alpha$ radiation) etc were used.

Preparation of Biosorbent: The chicken feathers (CF) collected from poultry farms were cleaned, washed in water and ethanol and cut into pieces of size $5 \mathrm{~mm}$. CF was modified using an equimolar mixture of methanol and $\mathrm{HCl}$ for two hours. $10 \mathrm{~g} \mathrm{CF}$ was mixed with $6 \%(\mathrm{v} / \mathrm{v}) \mathrm{CH}_{3} \mathrm{OH}$ and $2 \%(\mathrm{v} / \mathrm{v}) \mathrm{HCl}$ in a $250 \mathrm{ml}$ double necked flask and placed on a hot plate at $80 \mathrm{OC}$ with constant stirring for 3 hours. The reaction mixture was filtered, washed with distilled water and kept for drying [12]. Modified CF biosorbent was characterized by XRD \& FTIR [13].

Preparation of Adsorbate: The stock solution of chromium metal ion was prepared in the range $(1-10) \times 10^{-5} \mathrm{M}$.

Batch Adsorption Experiments: The adsorption studies were carried out in batches in different conditions of $\mathrm{pH}$, contact time, amount of adsorbent, temperature etc to check the propensity of adsorption process. In each $100 \mathrm{ml}$ conical flasks, $25 \mathrm{ml}$ of chromium solution was taken along with $100 \mathrm{mg}$ of adsorbent and shaken for 2 hours in an orbital shaker which was then kept for 24 hours 
for saturation. Thereafter supernatant liquid was filtered through Whatmann Filter Paper No.42 and the amount of chromium ion adsorbed was determined spectrophotometrically at $\lambda_{\max } 540 \mathrm{~nm}$. The amount of chromium ion adsorbed per unit biosorbent (mg metal/g of biosorbent) was calculated using Equations (1) \& (2)

$$
\begin{aligned}
& q e=\left(C_{0}-C_{e}\right) V / W(1) \\
& \text { Removal }(\%)=(\mathrm{Co}-\mathrm{Ce}) * 100 \mathrm{Co}
\end{aligned}
$$

Where $\mathrm{C}_{\mathrm{o}} \& \mathrm{C}_{\mathrm{e}}$ represent initial and final equilibrium concentrations (mg/L), $\mathrm{V}$ is the volume of Adsorbate taken, $\mathrm{W}$ is the weight of the biosorbent and $\mathrm{q}_{\mathrm{e}}$ is the amount of dye adsorbed at equilibrium.

\section{Results and Discussion}

\section{Characterization of the Biosorbent}

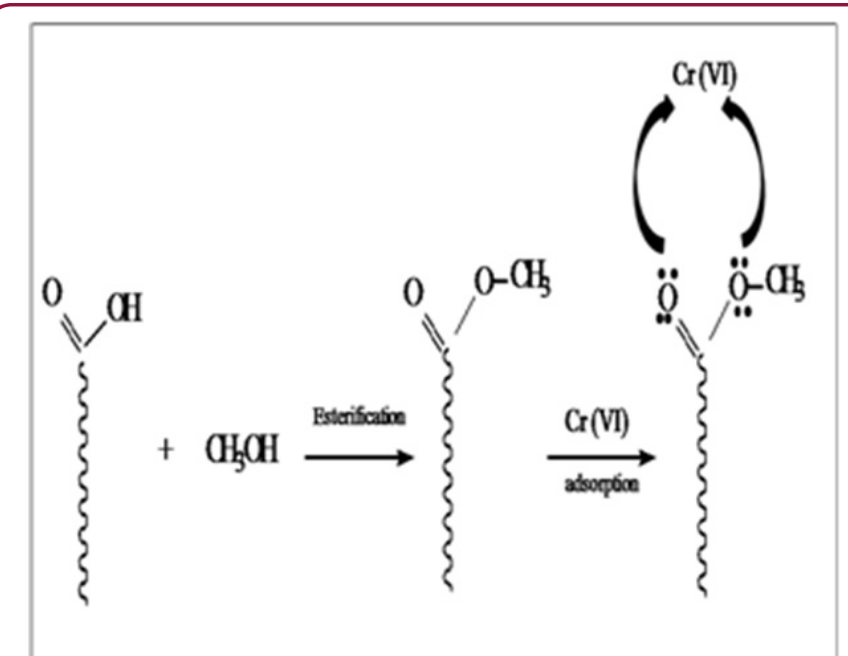

Figure 1: Chemical modification of chicken feather was carried out with methanol.

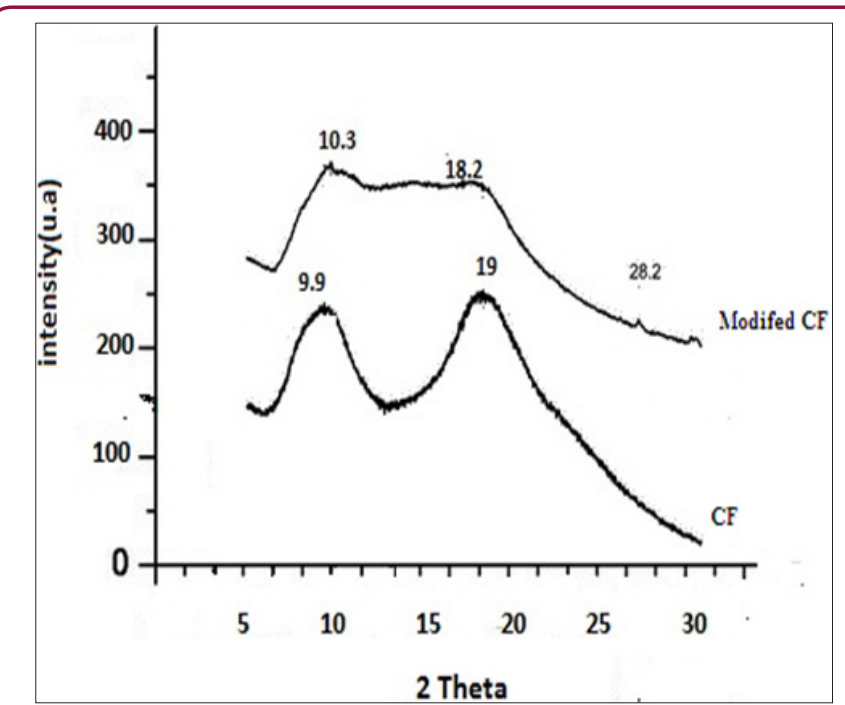

Figure 2: XRD patterns of $\mathrm{CF}$ and modified $\mathrm{CF}$.

Chemical modification of chicken feather was carried out with methanol as shown in Figure 1. Modified CF was characterized using XRD and FTIR. IR showed peaks in the range $1600-1700 \mathrm{~cm}^{-1}$ is due to $-\mathrm{NH}$ and $-\mathrm{C}=\mathrm{O}$ stretching vibrations of the amide group. In the case of modified CF, this peak becomes sharp at $1653 \mathrm{~cm}^{-1}$ due to the formation of random coils at the expense of a $\alpha$-helix and $\beta$-pleated sheets. The appearance of intense peak at $1740 \mathrm{~cm}^{-1}$ is due to the $-\mathrm{C}=0$ stretching vibration of the aliphatic ester of the modified CF [13]. XRD patterns of CF and modified CF are shown in Figure 2. The peak at 9.9 indicates $\alpha$ - helix configuration and a peak at 19 is due to stranded secondary structure. The modified CF peaks show decreased intensity. The slight shift of $2 \theta$ values confirms the decrease of the $\beta$-sheet content and partial cleavage of $\alpha$ - helix network [13] (Figures $1 \& 2$ ).

\section{Adsorption Studies}

Figure 3 shows the variation of adsorption efficiency of CF with $\mathrm{pH}$ for chromium ions it was found that maximum adsorption occurs at $\mathrm{pH}$ 6.0. The effect of variation of contact time on the adsorption of metal solution was also studied and optimum time was found to be 2 hours as shown in Figure 4. From Figure 5 we can see that adsorption of the metal by modified CF also depends on the amount of sorbent used and the optimum amount was found to be $100 \mathrm{mg}$.

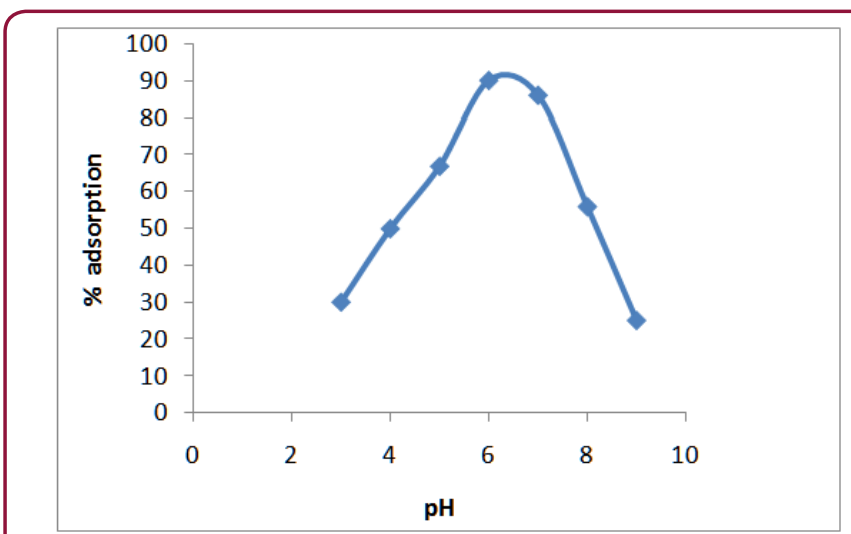

Figure 3: Variation of adsorption efficiency of $\mathrm{CF}$ with $\mathrm{pH}$ for chromium ions.

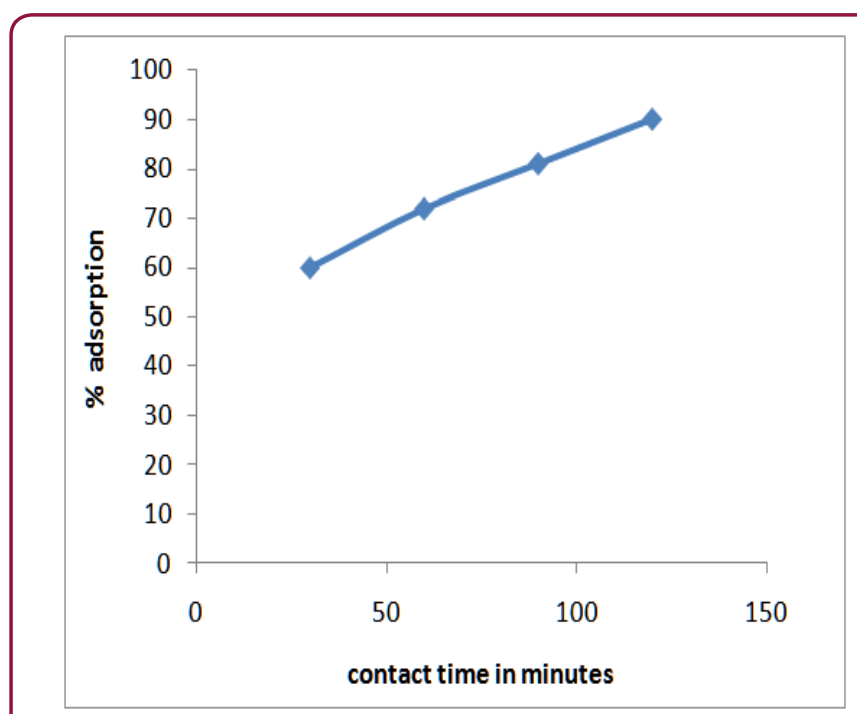

Figure 4: Effect of contact time on adsorption of matal.

\section{Adsorption kinetics}

Figure 6 shows the effect of contact time on adsorption of chromium onto modified CF at $100 \mathrm{mg} / \mathrm{L}$. Ho's pseudo-second order model (Eq. 3) was used. 


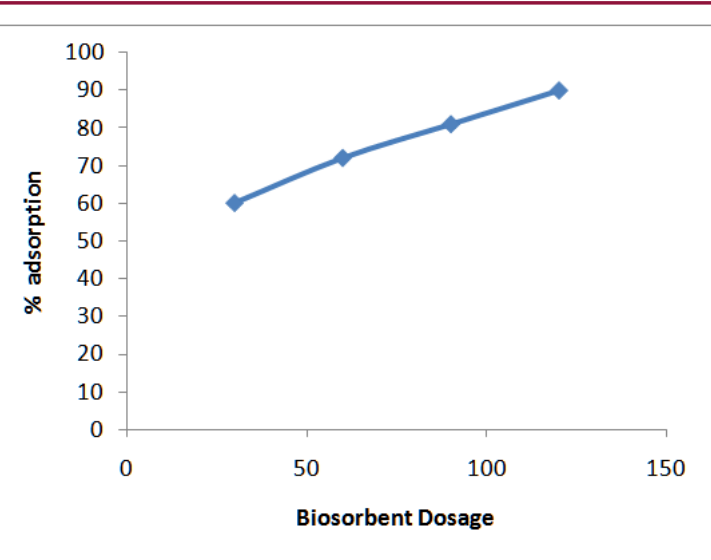

Figure 5: Optimum time was found to be 2 hours.

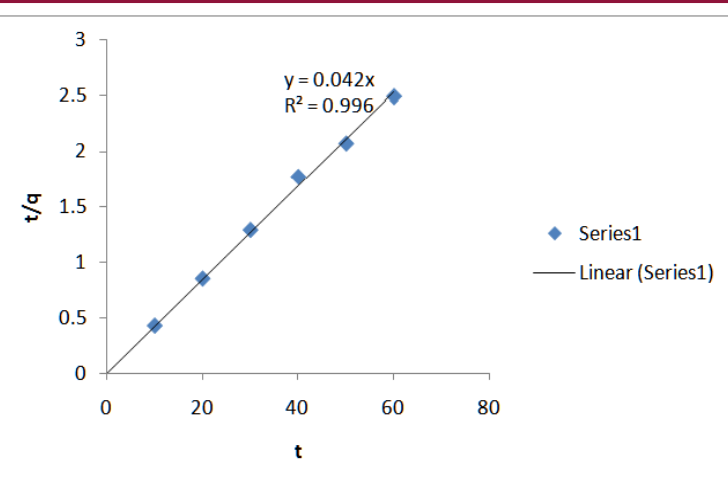

Figure 6: Effect of contact time on adsorption of chromium onto modified CF at $100 \mathrm{mg} / \mathrm{L}$.

$t / q t=1 / k_{2} q e^{2}+t / q e$

Kinetic studies show that the data fits well in the pseudosecond order plot and is shown in Figure 7.

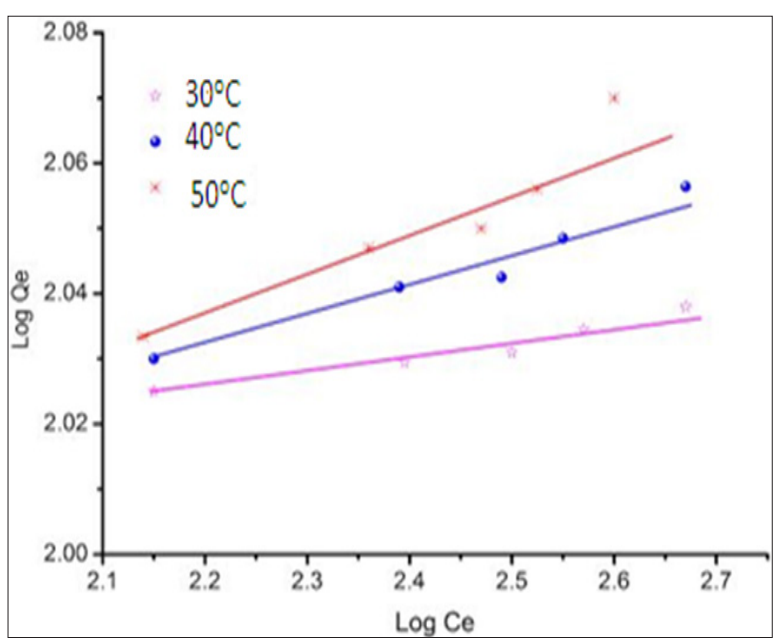

Figure 7: Kinetic studies show that the data fits well in the pseudo-second order plot.

\section{Equilibrium Studies}

The Freundlich adsorption isotherm was applied for the adsorption of metal on modified CF.

The Freundlich equation is represented as: $q e=K_{f} C 1 / n$

$\log q e=\log K_{f}+1 / n \log C$

Figure 7 is the plot of equilibrium isotherm for the sorption of chromium ions on chemically modified CF. The data fits well in the Freundlich isotherm. It also shows the dependence of temperature on the adsorption of chromium ions on the sorbent which confirms the endothermic nature of biosorption.

\section{Conclusion}

This study showed that modified chicken feather could be used as a potential biosorbent for the removal of $\mathrm{Cr}$ (VI) ions from aqueous solution. The biosorption process was affected by contact time, temperature, $\mathrm{p}^{\mathrm{H}}$ and biosorbent dosage. The thermodynamic studies indicated the endothermic nature of the biosorption process. The Freundlich isotherm model was found to be the most suitable in describing the equilibrium of the biosorption process. The kinetics of adsorption followed pseudo-second order model.

\section{References}

1. Nassar MM, YH Magdy (1997) Removal of different basic dyes from aqueous solution by adsorption on palm-fruit bunch particles. Chem Eng J 66(3): 223-226.

2. Agrahari S, Wadhwa N (2010) Degradation of chicken feather apoultry waste product by keratinolytic bacteria isolated fromdumping site at Ghazipur Poultry Processing plant. Int J Poult Sci 9(5): 482-489.

3. T Robinson, G McMullan, R Marchant, P Nigam (2001) Remediation of dyes in textile effluent: a critical review on current treatment technologies with a proposed alternative. Biores Technol 77(3): 247255.

4. VK Gupta, A Mittal, L Krishnan, V Gajbe (2004) Adsorption kinetics and column operations for the removal and recovery of malachite green from wastewater using bottom ash. Sep Purif Technol 40: 87-96.

5. A Mittal, L Krishnan, VK Gupta (2005) Use of waste materials-bottom ash and de-oiled soya, as potential adsorbents for the removal of amaranth from aqueous solutions. J Hazard Mater 117(2-3): 171-178.

6. CL Yang, J McGarrahan (2005) electrochemical coagulation for textile effluent decolorization. J Hazard Mater 127 (1-3): 40-47.

7. M Muruganandham, M Swaminathan (2006) Photocatalytic decolourization and degradation of Reactive Orange 4 by TiO2-UV process. Dyes Pigments 68: 133-142.

8. VK Gupta, A Mittal, L Kurup, J Mittal (2006) Adsorption of a hazardous dye, erythrosine, over hen feathers. J Colloid Interface Sci 304(1): 52-57.

9. A Mittal, J Hazard (2006) Adsorption kinetics of removal of a toxic dye, Malachite Green, from wastewater by using hen feathers. Mater 133(1): 196-202.

10.S Al-Asheh, F Banat, D Al-Rousan (2003) Determination of Lead using a feather modified carbon paste electrode by anodic stripping voltammetry. J Clean Prod 11: 321-326.

11. S Al-Asheh, F Banat, D Al-Rousan (2002) Adsorption of Copper, Zinc and Nickel Ions from Single and Binary Metal Ion Mixtures on to Chicken Feathers. Adsorpt Sci Technol 20: 849-864.

12. CL Yang, J McGarrahan (2005) electrochemical coagulation for textile effluent decolorization. J Hazard Mater 127(1-3): 40-47.

13. Aguayo-Villarreal A, Bonilla-Petriciolet A, Hernandez-Montoya V, Montes-Moran MA, Reynel-Avila HE (2011) Batch and columntudies of $\mathrm{Zn}^{2+}$ removal from aqueous solution using chicken feathers as sorbents. Chem Eng J 167(1): 67-76. 


Assets of Publishing with us
- Global archiving of articles

